\title{
Comparison of Diagnostic Accuracy of Colposcopic Findings Using Modified Reid Colposcopic Index with Histopathology in Cervical Lesions
}

\author{
Dr.Navya BN ${ }^{1}$, Dr.Rashmi B ${ }^{2}$, Dr.Ravikanth Go ${ }^{3}$, Dr. Sathyavathi R Alva ${ }^{4}$ \\ Associate Professor ${ }^{1}$, Postgraduate ${ }^{2}$, Assistant Professor ${ }^{3}$, Professor and Head ${ }^{4}$ \\ Department Of Pathology ${ }^{1,2,4}$, And Department Of Obstetrics And Gynaecology ${ }^{3}$ \\ K.V.G Medical College and Hospital, Sullia, D.K, Karnataka, India.
}

\begin{abstract}
:
Background: Colposcopy is a screening procedure used to detect pre invasive stages of carcinoma cervix. The accuracy of colposcopy is varied among colposcopists. To control the quality of colposcopy, Reid colposcopic index (RCI) was originated. However, the colposcopic features in RCI were subjective for some features.

Objective: The aim of the study was to compare the diagnostic accuracy of colposcopic findings using modified Reid Colposcopic Index with histopathology in cervical lesions.

Material and Methods: This was a prospective comparative study. A total number of 50 women who met the selection criteria were included in the study. Colposcopy was performed and results were evaluated using Reid colposcopic index. Colposcopic guided biopsy was taken in cases with abnormal colposcopic findings and finally the results of colposcopy and histopathology were compared.

Results: According to Reid colposcopic index, there were $54 \%$ benign cases, $18 \%$ women were diagnosed as CIN 1, 16 \% CIN 2 and 12\% as CIN 3 where as on histopathological correlation 58\% were benign, where as 12\%, 16\%, 14\% were diagnosed as CIN 1, CIN 2, CIN 3 respectively. The general accuracy rate was $92 \%$ and specificity of colposcopic examination was $90.48 \%$. The kappa value was $0.903(p=0.00 \leq 0.05$ ).

Conclusion: This study demonstrated high accuracy and correlation between colposcopy and histopathology.

Keywords: Colposcopy, Lugol's iodine, Reid colposcopic index
\end{abstract}

\section{Introduction}

Cervical cancer in women is the second most common cancer worldwide next to breast cancer. This is considered as a vital reproductive health problem in women and a prime cause of mortality among young women [1]. Global report published by WHO in 2014, shows almost 266000 women died from cancer of the cervix in the year 2012. According to a report, more than $83 \%$ of 49300 new cases of cervical cancer and higher mortality rate were seen in developing countries [2]. The main reason is lack of effective screening programmes which can detect and treat preliminary stage of this life threatening disease [3]. Cervical cancer has a long latent phase and can be easily prevented using early screening methods, including Pap smears, human papilloma virus (HPV) testing, cervical examination using acetic acid, Lugol's iodine and colposcopy [4,5].

he unique accessibility of the cervix to direct visualization and the possibility of cellular and tissue sampling has permitted extensive investigations on lesions of cervix [6]. Colposcopy is a worldwide-accepted method for detection of early cervical neoplasia [7].

Colposcopy is an optical method of visualizing lower female genital tract under bright illumination under stereoscopic vision. It is a simple non invasive OPD procedure which helps in determining the location, size and extent of abnormal cervical lesions and serves for detecting the site for biopsies and for selecting the most appropriate treatment [8]. Colposcopic grading using modified Reid's index makes colposcopy less subjective as it relies on critical analysis rather than pattern recall serving as a meaningful guide to histopathological severity [9].

Colposcopic guided biopsy of suspicious areas provides the final diagnosis and is taken as the gold standard in diagnosis of intra epithelial lesions,[10,11] and hence this study was undertaken to compare the diagnostic accuracy of colposcopic findings with histopathology in cervical lesions.

\section{Material and methods}

This was a prospective comparative study carried out in the Department of Pathology, K.V.G Medical College, Sullia, D.K, from January 2015 to June 2016. A total of 50 women who met the selection criteria were included in the study. 
Inclusion criteria: 1 . Women of age between 20-65 years. 2. Women with symptoms like vaginal discharge, post coital bleeding, postmenopausal bleeding, intermenstrual bleeding and persistent leucorrhoea. 3 . Women with normal looking cervix but symptomatic.

Exclusion criteria: 1.Women with bleeding at the time of examination. 2. Women with frank lesions. 3. Women with clinical evidence of acute pelvic infection. 4. Women who was previously treated for carcinoma cervix 5.Pregnant women.

Colposcopic findings were obtained from Department of Obstetrics and Gynaecology, KVG Medical college and Hospital, Sullia. Abnormal colposcopic findings if any like aceto-white areas, their margins and surface configurations, atypical vessels and abnormal iodine staining were analyzed and graded using modified Reid's index.

Table 1- Modified Reid's colposcopic Index- Adapted from Reid R, Scalzi and International Agency for Research in Cancer (IARC) manual [12].

\begin{tabular}{|c|c|c|c|}
\hline $\begin{array}{l}\text { Colposcopy } \\
\text { sign }\end{array}$ & Score 0 & Score 1 & Score 2 \\
\hline Margin & $\begin{array}{l}\text { Condylomatous } r \\
\text { micropapillary } \\
\text { Flocculated or feathered, } \\
\text { jagged, angular, satellite } \\
\text { lesion, AWA beyond original } \\
\text { squamo-coloumnar junction. }\end{array}$ & $\begin{array}{l}\text { Regular lesion with } \\
\text { smooth indistinct borders. }\end{array}$ & $\begin{array}{l}\text { Rolled, peeling edges, sharp } \\
\text { margins. }\end{array}$ \\
\hline Colour & $\begin{array}{l}\text { Shiny, snow white, areas of } \\
\text { faint (semi transparent) } \\
\text { whitening. }\end{array}$ & $\begin{array}{l}\text { Intermediate shade } \\
\text { (Shiny but grey white) }\end{array}$ & Dull, oyster grey \\
\hline Vessels & $\begin{array}{l}\text { Uniform, fine calibre non } \\
\text { dilated capillary loops fine } \\
\text { punctuation or mosaic. }\end{array}$ & $\begin{array}{l}\text { Absence if } \text { surface } \\
\text { vessels }\end{array}$ & $\begin{array}{l}\text { Definite, coarse punctuation } \\
\text { or mosaic. }\end{array}$ \\
\hline $\begin{array}{c}\text { Iodine } \\
\text { staining }\end{array}$ & $\begin{array}{l}\text { Any lesion } \\
\text { Mahagony brown; mustard } \\
\text { yellow stains by a minor } \\
\text { lesion (by first three criteria). }\end{array}$ & $\begin{array}{l}\text { Partial iodine uptake } \\
\text { (mottled pattern) }\end{array}$ & $\begin{array}{l}\text { Mustard yellow staining of a } \\
\text { significant lesion (an } \\
\text { acetowhite area scoring } 3 \text { or } \\
\text { more points by first three } \\
\text { criteria). }\end{array}$ \\
\hline
\end{tabular}

Table 2- Reid's colposcopic Index/Score (RCI) [12]

\begin{tabular}{|ll|}
\hline Score & Colposcopic findings \\
\hline $0-2$ & Likely to be CIN I \\
\hline $3-5$ & Likely to be CIN I -II \\
\hline $6-8$ & Likely to be CIN II - III \\
\hline
\end{tabular}

Biopsies were taken under colposcopy guidance by punch biopsy forceps for histopathological analysis. The punch biopsy specimen was allowed to fix in 10\% formalin, paraffin embedded by routine methods, sections were taken stained with hematoxylin and eosin stain and were examined under the microscope. Biopsy results were categorized as benign, CIN I, CIN II, CIN III and these values were taken as the gold standard.

Results of colposcopy were validated by calculating sensitivity, specificity, positive predictive value, negative predictive value in diagnosing histopathologically confirmed lesions.

Formulae used were sensitivity $=\mathrm{TP} / \mathrm{TP}+\mathrm{FN}$, specificity $=\mathrm{TN} / \mathrm{TN}+\mathrm{FP}$, positive predictive value $=$ $\mathrm{TP} / \mathrm{TP}+\mathrm{FP}$, negative predictive value $=\mathrm{TP} / \mathrm{TN}+\mathrm{FN}$, accuracy $=\mathrm{TP}+\mathrm{TN} /$ Total. Where $\mathrm{TP}-$ true positive, $\mathrm{TN}-$ true negative, FP - false positive, FN - false Negative.

\section{Results}

Histopathological findings according to age groups is shown in table 3. Most of the women were between $30-49$ years of age. High incidence of CIN II was found among the age group of 40 to 49 years and CIN III was found among $50-59$ years.

Table 3- Histopathological findings in different age groups

\begin{tabular}{|l|c|c|c|c|c|c|}
\hline $\begin{array}{l}\text { Age } \\
\text { (years ) }\end{array}$ & Benign & CIN I & CIN II & CIN III & Total & \% \\
\hline $\mathbf{2 0}-\mathbf{2 9}$ & 2 & 1 & - & - & 03 & 06 \\
\hline $\mathbf{3 0}-\mathbf{3 9}$ & 10 & 4 & 1 & 1 & 16 & 32 \\
\hline $\mathbf{4 0}-\mathbf{4 9}$ & 8 & 3 & 5 & 1 & 17 & 34 \\
\hline $\mathbf{5 0}-\mathbf{5 9}$ & 6 & 2 & 1 & 4 & 13 & 26 \\
\hline $\mathbf{6 0}-\mathbf{6 9}$ & 1 & - & - & - & 01 & 02 \\
\hline Total & 27 & 10 & 7 & 6 & 50 & 100 \\
\hline
\end{tabular}


According to Reid colposcopic index, there were $54 \%$ benign cases, $18 \%$ women were diagnosed as CIN I, $16 \%$ CIN II and $12 \%$ as CIN III where as on histopathological correlation $58 \%$ were benign showing chronic erosive cervicitis, where as $12 \%, 16 \%, 14 \%$ were diagnosed as CIN I (mild dysplasia), CIN II (moderate dysplasia), CIN III (severe dysplasia) respectively (Table 4). The general accuracy rate was 92\% (Table 5).

Table 4- Correlation of colposcopy with histopathology

\begin{tabular}{|c|c|c|c|c|c|}
\hline \multirow[b]{2}{*}{ Reid Index } & \multicolumn{4}{|c|}{ Pathology Result } & \multirow[b]{2}{*}{ Total } \\
\hline & Benign & CIN I & CIN II & CIN III & \\
\hline Benign & $27(54 \%)$ & - & - & - & $27(54 \%)$ \\
\hline CIN I & $1(2 \%)$ & $6(12 \%)$ & $1(2 \%)$ & $1(2 \%)$ & $9(18 \%)$ \\
\hline CIN II & $1(2 \%)$ & - & $7(14 \%)$ & - & $8(16 \%)$ \\
\hline CIN III & - & - & - & $6(12 \%)$ & $6(12)$ \\
\hline Total & $29(58 \%)$ & $6(12 \%)$ & $8(16 \%)$ & $7(14 \%)$ & $50(100 \%)$ \\
\hline
\end{tabular}

Table 5- Relation between RCI and histopathological results

\begin{tabular}{|l|c|c|c|c|}
\hline $\begin{array}{c}\text { Colposcopy Results } \\
\text { Reid Index }\end{array}$ & $\begin{array}{l}\text { Over } \\
\text { estimation }\end{array}$ & $\begin{array}{l}\text { Under } \\
\text { estimation }\end{array}$ & $\begin{array}{l}\text { Accurate } \\
\text { estimation }\end{array}$ & Total \\
\hline Benign & - & - & 27 & $27(34 \%)$ \\
\hline CIN I & 1 & 2 & 6 & $9(18 \%)$ \\
\hline CIN II & 1 & - & 7 & $8(16 \%)$ \\
\hline CIN III & - & - & 6 & $6(12 \%)$ \\
\hline Total & $2(4 \%)$ & 2 & $46(92 \%)$ & $50(100 \%)$ \\
\hline
\end{tabular}

The sensitivity and the specificity of colposcopy were $90.48 \%$ and $93.10 \%$ respectively. The positive predictive value and the negative predictive value of colposcopy in the present study were $90.48 \%$ and $65.51 \%$ respectively.The general accuracy rate was $92 \%$ in the present study (Table 6).

Table 6- Sensitivity and specificity of colposcopy

\begin{tabular}{|l|c|c|c|}
\hline \multicolumn{3}{|c|}{ Histopathology } & \\
\hline Colposcopy & Positive & Negative & Total \\
\hline Positive & $19(38 \%)$ & $2(4 \%)$ & $21(42 \%)$ \\
\hline Negative & $2(4 \%)$ & $27(54 \%)$ & $29(58 \%)$ \\
\hline Total & $21(42 \%)$ & $29(58 \%)$ & $50(100 \%)$ \\
\hline
\end{tabular}

The kappa value was calculated to measure agreement between RCI and histopathology findings and the overall correlation was $0.903(\mathrm{p}=0.00 \leq 0.05)$, indicating a strong agreement.
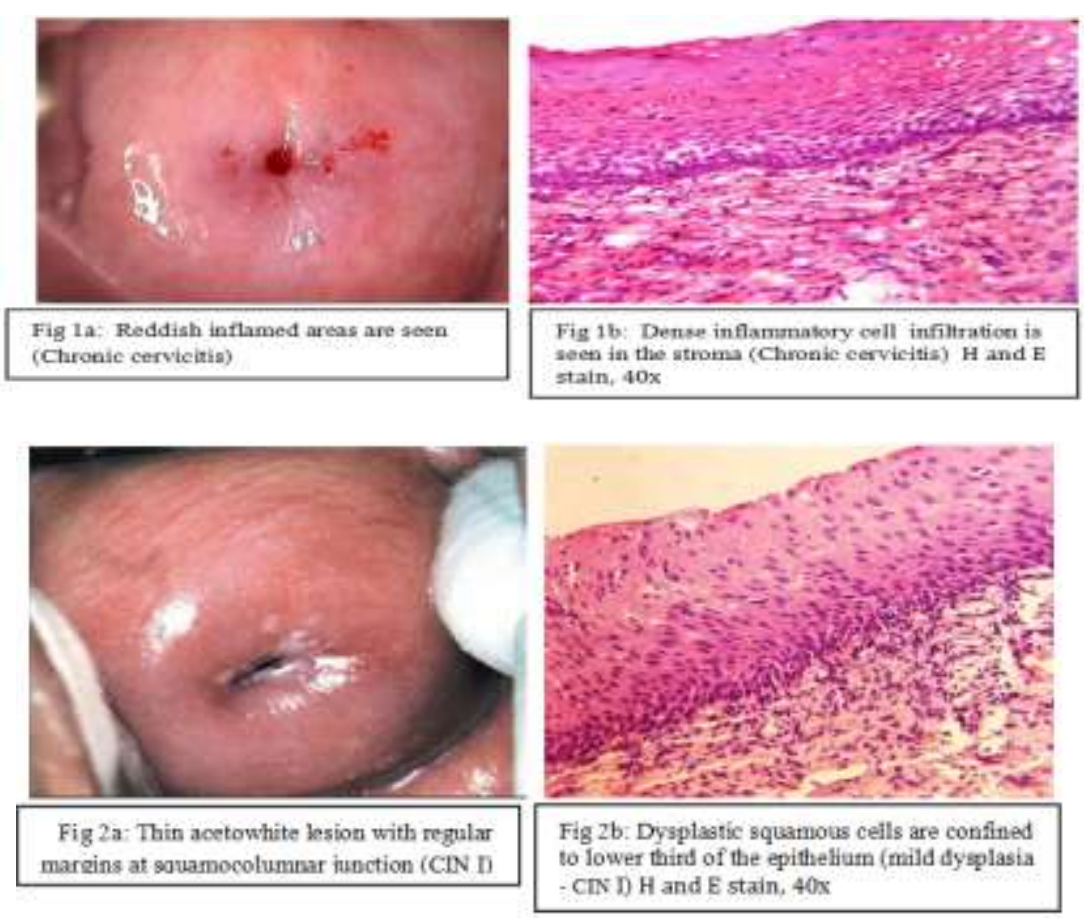


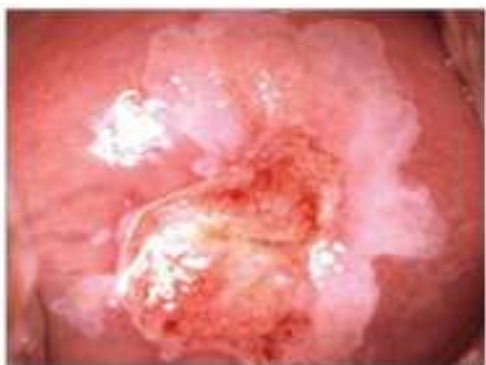

Fig 3a: A dense acetonhite lesico with coarse punctuation and mosaics (CIN II)

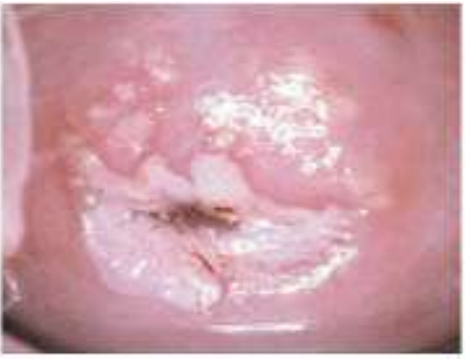

Fig 4a: A circumorifecial dense opaque acetowhive area with coarse mosaics (CIN

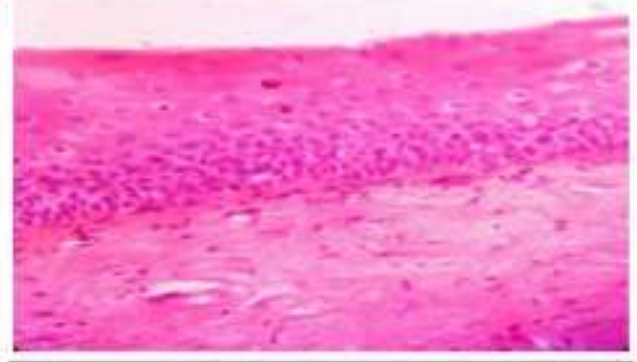

Fig 3b: Dysplastic squamous cells are found in the lower two-thitds of the epithelinm (moderate dysplasia - CDV II) H and $\mathrm{E}$ stain, $40 \mathrm{x}$

\section{Discussion}

Cervical cancer has an uneven geographic distribution with majority of cases being in developing countries. Declining trends in last few decades is attributed to the implementation of organised screening programmes by Pap smear. Colposcopy as a clinical method has been of proven accuracy in evaluating patients with abnormal cervical cytology [13].

However, colposcopy is not a definitive diagnostic test. There can be variability in different inspections performed by same colposcopist and in same inspection performed by different colposcopists. Inadequate colposcopic examination may require histopathological assessment as well, even in case of normal findings on colposcopic examination or mild cases of HPV infection [4].

In the present study, lesions were diagnosed in patients aged between 20 to 69 years, the maximum number of patients was in the age group of 30-49 years (66\%). Similar age incidence was noticed in a study done by Ancuta Boicea et al [14].

In our study regarding age distribution, High incidence of CIN II was found among the age group of 40 to 49 years and CIN III was found among $50-59$ years, similar to Hegde et al [7].

Among 50 cases in our study, $27(54 \%)$ had normal colposcopic findings and $18 \%$ cases were diagnosed as CIN I (mild dysplasia), $16 \%$ as CIN II (moderate dysplasia) and 14\% as CIN III (severe dysplasia). However we found good correlation with histopathology for CIN III as compared to CIN I and CIN II which was similar to a study done by Durdi GS et al [15].

In our study, there was over estimation and under estimation of 2 cases each on colposcopy. Over estmation of two cases on colposcopy includes CIN I (1case) and CIN II (1 case) which was diagnosed as chronic non specific cervicitis on histopathology while under estimation was seen in two cases of CIN I on colposcopy which was diagnosed as CIN II ( 1 case ) and CIN III ( 1 case) on histopathology and hence the accuracy of coloposcopic directed biopsies in our study was $92 \%$ which was comparable to that of the study conducted by Gupta V et al [13]. Under estimation may occur when high grade lesion may be over looked, which may appear as an inner border of sharp acetowhite demarcation within a less opaque acetowhite area [16].

The sensitivity and specificity of colposcopy in our study was $90.48 \%$ and $93.10 \%$ respectively with a general accuracy rate of $92 \%$ which was similar to Deshpande Sonali et al [10].

The main goal of cervical screening is to identify women with moderate - severely dysplastic lesions (HSIL) which are considered to be the true precursors of invasive cancer and require treatment, thus ultimately decreasing morbidity and mortality due to cervical cancer [8]. Colposcope helps to visualise the cervix and distinguish normal from abnormal areas and to take direct biopsies from abnormal areas for further pathological evaluation [17]. 


\section{Conclusion}

This study demonstrated high accuracy and correlation between colposcopy and histopathology. There were cases of under and over diagnosis, so the benefit of colposcopy and directed biopsy is helpful to avoid over treatment of low-grade lesion and under treatment of high-grade lesion.

\section{References}

[1]. Bhalerao A, Kulkarni S, Ghiki S, Kawthalkar A, et al, Correlation of Pap smear, Colposcopy and Histopathology in Women with Unhealthy Cervix. J South Asian Fededr Obst Gynae 2012;4(2):97-98

[2]. Naik R, Minj MM, Panda R, Satpathi S, Behera PK, Panda KM. Cytohistological correlation and accuracy of the Pap smear test in diagnosis of cervical lesions: a hospital based cross sectional study from Odisha, India. Medical science. 2015,3(3):242-9

[3]. Parveen K, Begum MF, Momen A, Ara S et al. Cervical Pap smear examination - A cost-effective screening

[4]. test to reduce the mortality of cervical cancer. J. Dhaka National Med. Coll. Hos. 2013; 19(01): 49-53

[5]. Kaban I, Cengiz C, Kaban A, Yildiz S et al Agreement between colposcopy results using

[6]. the Reid Colposcopic Index and histopathology Ginekol Pol. 2015, 86, 537-540

[7]. Shanmugham D, Vijay A, Rangaswamy T Colposcopic Evaluation of Patients with Persistent Inflammatory Pap Smear. Sch. J. App. Med. Sci., 2014; 2(3B):1010-1013

[8]. Zainab S. Nayani, Pravin Chandra Hendre. "Comparision and Correlation of Pap Smear with Colposcopy and Histopathiology in Evaluation of Cervix". Journal of Evolution of Medical and Dental Sciences 2015; Vol. 4, Issue 53, July 02; Page: $9236-9247$

[9]. Hegde D, Shetty H, Shetty PK, Rai S. Diagnostic value of acetic acid comparing with conventional Pap smear in the detection of colposcopic biopsy-proved CIN. J Can Res Ther 2011;7:454-8.

[10]. Chaudari RD, Inamdar SA, Hariharan C. Correlation of diagnostic efficacy of unhealthy cervix by cytology, colposcopy and histopathology in women of rural areas Int J Reprod Contracept Obstet Gynecol. 2014 Mar;3(1):213-218

[11]. Aue-Aungkul A, Suprasert P, Reid Colposcopic Index Evaluation: Comparison of General and Oncologic Gynecologists. Asian Pacific Journal of Cancer Prevention, Vol 16, 2015 5001-5004

[12]. Deshpande Sonali, Yelikar Kanan, Andurkar Smita, Dahitankar Suvarna. "Role of Colposcopy using Modified Reid's Index in Screening of Cervical Cancer in Women with Abnormal Cervix on Naked Eye Examination”. Journal of Evolution of Medical and Dental Sciences 2014; Vol. 3, Issue 04, January 27; Page: 902-906,

[13]. Ramesh G, Sudha ., Jayashree AK, Padmini J Colposcopic Evaluation of the Unhealthy Cervix.

[14]. Journal of Clinical and Diagnostic Research. 2012 August, Vol-6(6): 1026-1028

[15]. Sellors JW, Sankaranarayanan R (2003). Colposcopy and Treatment on Cervical Intraepithelial Neoplasia : A Beginners' Manual. IARCPress, Lyon, France: page: 67

[16]. Gupta V, Tandon A, Nanda A, Sharma A, Bansal N. Colposcopic evaluation of cervical lesions: a prospective study. Int J Clin Trials 2014;1:110-3.

[17]. Boicea A, Patrascu A, Surlin V, Iliescu D et al Correlations between colposcopy and histologic

[18]. results from colposcopically directed biopsy in cervical precancerous lesions. Rom J Morphol Embryol 2012, 53(3 Suppl):735-741

[19]. Durdi GS, Sherigar BY, Dala AM1, Desai BR, Malur PR Correlation of colposcopy using Reid colposcopic index with histopathology- a prospective study J Turkish-German Gynecol Assoc 2009; 10: 205-7

[20]. Scheungraber C, Glutig K, Fechtel B, Kuehne-Heid R et al Inner Border-Specific and Significant Colposcopic sign for Moderate or severe Dysplasia ( Cervical Intraepithelial Neoplasia 2 or 3). Obstetrical and Gynecological Survey. 2009; 64(4):234-235

[21]. Akhter S, Bari A, Hayat Z Variability study between Pap smear, Colposcopy and Cervical Histopathology findings. J Pak Med Assoc Vol. 65, No. 12, December 2015 